\title{
(C) OPEN ACCESS \\ Patient safety culture in China: a case study in an outpatient setting in Beijing
}

\author{
Chaojie Liu, ${ }^{1}$ Weiwei Liu, ${ }^{2}$ Yuanyuan Wang, ${ }^{2}$ Zhihong Zhang, ${ }^{2}$ \\ Peng Wang ${ }^{2}$
}

- Additional material is published online only. To view please visit the journal online (http://dx.doi.org/10.1136/bmjqs2013-002172)

${ }^{1}$ China Health Program, La Trobe University, Melbourne, Victoria, Australia

${ }^{2}$ Peking University Third Hospital, Beijing, China

\section{Correspondence to} Professor Weiwei Liu, Second Outpatient Department, Peking University Third Hospital, Beijing 100096, China; vivian_liu@bjmu.edu.cn

Received 23 May 2013 Revised 17 November 2013 Accepted 28 November 2013 Published Online First

18 December 2013

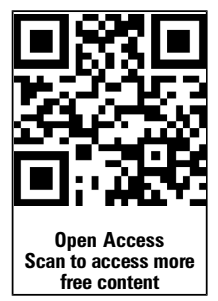

CrossMark

To cite: Liu C, Liu W, Wang Y, et al. BMJ Qual Saf 2014:23:556-564.

\begin{abstract}
Objectives To investigate the patient safety culture in an outpatient setting in Beijing and explore the meaning and implications of the safety culture from the perspective of health workers and patients.
\end{abstract}

Methods A mixed methods approach involving a questionnaire survey and in-depth interviews was adopted. Among the 410 invited staff members, 318 completed the Hospital Survey of Patient Safety Culture (HSOPC). Patient safety culture was described using 12 subscale scores. Inter-subscale correlation analysis, ANOVA and stepwise multivariate regression analyses were performed to identify the determinants of the patient safety culture scores. Interviewees included 22 patients selected through opportunity sampling and 27 staff members selected through purposive sampling. The interview data were analysed thematically.

Results The survey respondents perceived high levels of unsafe care but had personally reported few events. Lack of 'communication openness' was identified as a major safety culture problem, and a perception of 'penalty' was the greatest barrier to the encouragement of error reporting. Cohesive 'teamwork within units', while found to be an area of strength, conversely served as a protective and defensive mechanism for medical practice. Low levels of trust between providers and consumers and lack of management support constituted an obstacle to building a positive patient safety culture.

Conclusions This study in China demonstrates that a punitive approach to error is still widespread despite increasing awareness of unsafe care, and managers have been slow in acknowledging the importance of building a positive patient safety culture. Strong 'teamwork within units', a common area of strength, could fuel the concealment of errors.

\section{INTRODUCTION}

Since the release of the Institute of Medicine report 'To Err is Human', extensive patient safety studies have been undertaken in developed countries. $^{2-8}$ Despite a lack of research, patient safety in developing countries, including in China, is believed to be a serious concern. ${ }^{9}$ Empirical evidence has shown that the risk of adverse events such as unsafe injections and acquired infection from healthcare is 2-20 times higher in developing countries than in countries in the developed world. ${ }^{10}$ The Chinese Hospital Association estimates that hospital adverse events affect 1.6-7.6 million patients each year across the nation. 9

Patient safety depends on an organisational culture that harnesses the commitment of all staff. Such an aspect of organisational culture is usually termed 'patient safety culture', where members of the organisation share values, beliefs and norms related to patient safety. ${ }^{11}$ It shapes the commitment to and the style of proficiency of safety practice. ${ }^{12} 13$

There is an increasing consensus on the importance of creating an open and nonpunitive approach towards errors and patient safety in health organisations, ${ }^{14} 15$ because such a culture encourages reporting of events for learning purposes ${ }^{16-20}$ and influences the motivation of clinicians to engage in safer practices. ${ }^{16}$ A positive patient safety culture improves patient outcomes, such as reducing hospital-acquired infections and other adverse events. $^{13} 21$

Over the past decade, researchers have developed several instruments to assess patient safety culture. ${ }^{22-26}$ Despite largely independent development, these instruments feature similar psychometric properties and measure similar dimensions. ${ }^{22} 23$ 
In a recent review Sammer et $a l^{27}$ categorised hospital culture of patient safety into seven key aspects: leadership, teamwork, evidence-based, communication, learning, just and patient-centred. Studies have revealed differences in patient safety culture across professions, units, hospitals and countries. ${ }^{9}{ }^{12} 28-32$ The implications of such differences and the underlying reasons are less clear, although there is some speculation that these differences might be related to the structural and procedural characteristics of individual services and influenced by the national culture. ${ }^{12} 33$

Surprisingly, little attention has been paid in international literature to safety culture in terms of outpatient care. ${ }^{834}$ Arguably, there are significant risks associated with outpatient care, particularly in clinics with high throughput and limited direct supervision of less experienced staff. Some studies suggest that up to $20 \%$ of all people may have experienced medical errors related to outpatient care. ${ }^{35-37}$ The diversity and variation in scope, structure and infrastructure in outpatient care may foster more opportunity for error. Unlike an inpatient environment where services usually focus on an acute illness during a short episode, outpatient care often deals with a wider range of simultaneous and/or chronic health problems of a particular individual over an extended period.

This study aims to investigate patient safety culture in an outpatient setting in Beijing and explore the meaning and implications of the safety culture through the lens of health workers and patients. In China, both hospitals and community facilities may serve as the first point of contact for patient care. According to the 2011 national health statistics report, ${ }^{38}$ Chinese hospitals accounted for about 35\% of all outpatient visits. This high outpatient care throughput in hospitals has resulted in crowded environments and heavy workloads of hospital staff, especially in large tertiary hospitals. Despite inpatient care responsibilities and associated workload (an average of 2.2 patients per day), hospital doctors in China provided on average 6.4 outpatient consultations per day, three consultations fewer than those working in a community facility without (or with few) inpatient duties. Zhao and Chen ${ }^{39}$ suggest that, in Chinese hospitals, outpatient and emergency departments have the highest frequency of adverse events.

\section{METHODS}

The research was undertaken in two outpatient clinics attached to a tertiary hospital in Beijing. The data collection period commenced in February and concluded in May 2010. Most of the patients visiting the clinics were self-referred. Both clinics had a very high throughput, with each physician seeing an average of 47 patients a day. The total volume of outpatient visits reached 8000 a day (more details about the two clinics can be found in appendices 1 and 2 in the online supplement).
A mixed methods approach involving a questionnaire survey and in-depth interview was adopted. The questionnaire measured dimensional scores of patient safety culture. Over the past 5 years there has been a surge in patient safety culture studies, most using a scale to quantify the scores of safety culture. ${ }^{40}$ However, the meaning of those scores is not selfexplanatory. The implication of any particular set of shared norms of medical practice (culture) for patient outcomes depends in part upon how patients perceive and respond to such practice. ${ }^{12} 29$ If the norms of practice are perceived as centred around the interests of the medical workers and/or their rationale is not understood/endorsed by patients, such forms of practice may not be able to deliver their intended benefits to the patients. The lack of a shared understanding could lead to fear, confusion and suspicion of patients and serious conflicts between patients and medical workers. In this study we attempted to explore the meaning and implications of patient safety culture through the lens of patients and health workers. An in-depth interview approach serves well for this purpose.

\section{Questionnaire survey}

The Hospital Survey of Patient Safety Culture (HSOPC) instrument developed by the Agency for Healthcare Research and Quality (AHRQ) was used in this study. ${ }^{24}$ It contains 12 subscales, eight of which are unit-level measures (manager expectations and actions promoting safety, organisational learning, teamwork within units, communication openness, feedback and communication about errors, nonpunitive response to errors, staffing and management support for patient safety), two are hospital-wide measures (teamwork across units and handoffs and transitions) and two are risk awareness measures (overall perceptions of safety and frequency of event reporting (institution wide)). Each subscale consists of 3-5 questions rated on a 5 -point Likert scale. To make results easier to interpret, the AHRQ recommends an 'average positive' scoring system for calculating subscale scores. ${ }^{24-26} 28-3032$ The responses to each question were given a score, with 1 representing a positive culture in favour of patient safety and 0 representing an unfavourable culture. A mean score was computed for each subscale; higher scores indicate a more favourable culture in patient safety. Although a total score based on the Likert scale may have contained more respondent information because it reflects the 5 -point response to each item, its meaning is not clear and thus has not been recommended by the AHRQ. The questionnaire also contains questions about demographic characteristics, workloads and work experiences, and personal rating on patient safety and number of events reported over the past 12 months of the respondents. 
The HSOPC has been widely used in assessing patient safety culture. It has been validated in a number of countries ${ }^{24-26}$ including a translated Chinese version in Taiwan and mainland China. ${ }^{9} 2932$ In this study, the Cronbach $\alpha$ coefficients of the HSOPC subscales ranged from 0.37 to 0.81 , slightly higher than those reported elsewhere in Chinese hospitals. ${ }^{9} 12$ The survey was completely anonymous and was voluntary. A total of 410 questionnaires were distributed to the staff members in the two clinics, with a return or response from 318 (77.5\%).

The questionnaire data were analysed using SPSS V.17.0. All questionnaires have been included in the statistical analyses. However, with regard to a specific statistical test, questionnaires with a missing value were excluded from the relevant analysis. We performed bivariate correlation analyses between the HSOPC subscales. A correlation with a Pearson coefficient $(r)$ of $<0.3$ is considered weak and $>0.7$ is considered strong. ${ }^{30}$ ANOVA and multivariate regression analyses identified independent variables with a significant association with patient safety culture. In the analyses the dependent variables were the mean scores for each of the HSOPC subscales. Several factors identified in previous studies as predictors of patient safety culture were tested as independent variables, including demographic characteristics (age and sex), job characteristics (profession and qualification), work experience (career length, organisation and unit) and workload (working hours). ${ }^{9} 32$ These independent variables were treated as dummy variables. We did not make a presumption about the direction and strength of associations between these independent variables and the subscales of the HSOPC since such associations are not always straightforward ${ }^{41}$ and are likely to be context-specific. ${ }^{33}$ We also analysed the associations of the HSOPC subscales with two of the putative outcome measures: personal rating on patient safety and number of events reported by the respondents. Least significance difference was applied in the ANOVA for post hoc pairwise comparisons. The multivariate regression analyses adopted a stepwise approach using entrance/exit tolerance of $0.05 / 0.10 .^{42}$

Just under half the respondents were aged $\leq 35$ years and the majority were women. Doctors were the single largest sub-professional group of respondents (39\%). Over $90 \%$ of respondents had direct contact with patients. More than half of the respondents had worked for the current employer for more than 5 years. About $69 \%$ of respondents had an average weekly workload of 40-59 h (more details about the characteristics of the survey respondents can be found in appendix 3 in the online supplement).

\section{In-depth interviews}

In-depth interviews were undertaken with hospital staff and patients to examine (1) how each group perceives patient safety; (2) what actions patients and health providers take to ensure patient safety; and (3) how patients and providers make decisions on their course of actions.

We used a purposive sampling technique to recruit staff interviewees, who were selected based on a balance of gender, age, profession and work experience. Opportunity sampling technique was employed for recruiting patient interviewees. Patients (or their parents) aged $>18$ years who visited the clinics during the survey period were invited to participate. Those with an intellectual disability or frailty deemed unable to consent or where the burden of participation was considered excessive were excluded.

Informed consent was obtained prior to each interview. A prompt list of questions was developed (see details in appendices 4 and 5 in the online supplement), but the interview was kept flexible. Each interview took about $1 \mathrm{~h}$ and was digitally recorded. A research assistant transcribed the recorded data as soon as each interview was completed so that data analysis could be performed to inform the needs of further interviews. The accuracy of the transcriptions was reviewed (and corrected if necessary) by the researchers.

Data coding was achieved using NVivo. Keywords in the expression of the participants were first extracted as a primary code. The primary codes expressing similar ideas were compared and then either rephrased into a more consistent code or divided into two or more different codes which were then categorised. The selective coding related the categories to each other via a combination of deductive (using Sammer's safety culture model ${ }^{27}$ and the HSOPC subscales as a coding framework) and inductive thinking. ${ }^{43}$ Coding by individual researchers was discussed in research team seminars, as were the differences and similarities between the findings of the interviews and the questionnaire survey.

A total of 22 patients, 15 health workers and 12 health managers eventually completed the interviews (more details about the characteristics of the interviewees can be found in appendix 6 in the online supplement).

\section{RESULTS}

\section{Poor patient safety outcomes are evident}

Some $20 \%$ of questionnaire respondents (health workers) graded patient safety as 'extremely poor'. However, the number of events reported by the respondents personally was very low. Over the past 12 months, $67.4 \%$ of respondents did not report an adverse event, $21.4 \%$ reported $1-2$ events and 11\% reported $\geq 3$ events. Similarly, low scores were found in 'overall perception of patient safety' $(0.52)$ and 'frequency of event reporting' (0.38) of the HSOPC.

The interviews revealed that both health workers and patients were aware of the seriousness of poor patient safety. However, they had different views 
regarding the nature of the patient safety problem. Health workers tended to see patient safety risk as a result of the complex nature of outpatient care, inappropriate staffing and heavy workload, staff incompetence, policies that create perverse incentives and lack of patient support. In contrast, patients tended to see health workers driven by self-interest and to blame them for making errors, which typically involved inappropriate services and excessive tests. While health workers saw inappropriate or overservicing as an indication of lack of competency or necessary defensive practice, patients assumed they were directed to maximising revenues (table 1).

\section{Poor patient safety culture is associated with poor patient safety outcome}

The personal rating of patient safety was associated with all patient safety culture subscales. Those who perceived themselves as working in a more positive safety culture were more likely to judge patient safety as good (see appendix 7 in online supplement). However, patient safety culture was given a poor grade by the respondents of the questionnaire (health workers). They reported very low scores in 'nonpunitive response to errors' (0.23), 'adequacy of staffing to support good patient care' (0.29) and 'communication openness' (0.31), despite relatively high scores in 'teamwork within units' $(0.85)$ and 'organisational learning' (0.71).

Strong teamwork within units reflects internal protection

According to the interviewees, the high scores in 'teamwork within units' can be explained as strong internal protection. Health workers admitted that, within a unit, staff members protected each other, in particular when patients were present. With regard to correction of error, they took every precaution not to offend colleagues.

You don't need to point out your colleagues' error in front of patients. If a colleague doesn't wear a mask in a medical procedure, why should you be bothered to point it out if it would not lead to real harm to the patient? It is not necessary. Every doctor is cautious in practice. They don't want to hurt patients ... The older you are, the more cautious you become. It is like a growing up process. (Physician)

I will not report errors to managers. I don't want to cause trouble. I may talk to my colleagues in private because we may have made similar errors ... But if a doctor prescribed more medicine than what was restricted to, a colleague might point it out. Because if not, it will be identified later for sure, and the doctor will be blamed by the manager and there will be a financial penalty. It is for the good of our colleagues. (Nurse)

However, such protection did not apply as strongly to those outside of their unit or organisation. Unfavourable comments on advice given by an external doctor could occur in the context of defending one's own judgement or practice.

Punitive approach to error

Health workers preferred not to report errors. The supportive culture within units fuelled the concealment of errors. Careful considerations were taken when staff determined whether or not to report errors.

I would not criticise my subordinate without careful consideration. I point out errors only for the sake of

Table 1 Perceptions of risks of patient safety in outpatient care

\begin{tabular}{lll}
\hline Category & Perceptions of health providers & Perceptions of patients \\
\hline Characteristics of & Multiple service providers; multiple processes; intermittent & No idea how the system works \\
outpatient care delivery & contacts; multiple problems; patients can walk away anytime &
\end{tabular}

system

Working/service environment

Provider-patient communication

Decision-making by providers

Decision-making by patients
No continuing patient-provider relationship; no complete medical records; not sharing information; lack of interprofessional communication; not enough time; no medication supervision; excessive policy intervention; understaffing; seriously overloaded; high stress level

Patients do not disclose essential information; poor literacy of patients; no patient identification system; forged identification; patients talk too much but do not get to point; wrong information shared between patients; waste of time; patients not reasonable; patients too demanding; patients not understanding; patients have too high expectation

Poor knowledge; lack of experience; one-off contact

Do not read medication instructions; depend on unreliable information; negative influence from other patients; demand immediate solution; seek second opinion; use one doctor to argue against another
Insecure; crowded; scared of being infected

Doctors show impatience; doctors do not ask; doctors do not listen; patients being seen as making trouble; no chance to ask questions; being deterred from arguing for our own interest

Over-service for profit; without thinking about how expensive; without thinking about adverse effects; depend on machines; over-prescribe; do not care about things beyond their specialty; money grab machine

Follow instructions from doctors; self-protection; always being passive; trust public media; seek advice from fellow patients; do not know how to choose; prefer to have same doctor 
preventing serious consequences. You don't want to give people an impression of being a whistle blower ... For my colleagues, I have to be $100 \%$ sure that they are making mistakes before I take a gentle approach to remind them, such as touching or whispering. I want them to know I am helping them ... If mistakes have been made, I need to look at the potential consequences. If no serious consequences, you just remind your colleagues in private. I would only go to our managers when serious consequences are likely to occur. (Nurse Manager)

Managers acknowledged that punishing individuals was considered to be an effective measure to motivate learning.

We punished our staff for errors, not because we wanted to do so. We just followed instructions from the senior managers. It is not up to us to make a decision. There is no communication whatsoever. (Manager)

The questionnaire survey verified the findings from the in-depth interview: $70 \%$ of respondents agreed that they would report self-errors while only one-third of respondents would report errors made by their colleagues. A little more than half of the respondents would report management errors (see appendix 8 in online supplement). The regression analyses showed that the number of events personally reported was significantly associated with a positive perception of 'feedback and communication about error' and 'nonpunitive response to error' (see appendix 7 in online supplement). However, about $38 \%$ of respondents expressed no confidence in a 'no penalty' policy regarding reported errors, which was also the primary reason for not reporting self-errors. More than half of respondents were concerned about being seen as a whistle blower, which would be detrimental to their collegial relationships. Approximately one-third of respondents felt no obligation to report errors made by their colleagues or managerial arrangements. Fewer than $63 \%$ of respondents would be open to using an anonymous reporting system (see appendix 8 in online supplement).

Poor communication

The interviews revealed that both health workers and patients acknowledged difficulties in communication, although they regarded the underlying reasons differently. Patients blamed doctors for 'impatience', felt that they were not in a position to initiate effective communication and believed they had no choice other than to seek a second opinion. Health workers believed that communication was poor because they were too busy, patients had poor literacy and did not respect their professional authority.

Communication openness was seriously jeopardised by the lack of trust between health workers and patients and, as a result, the defensive practice adopted by medical practitioners.
They (patients) see more than one doctor at a visit. They just don't trust any of us. They want comparisons and verifications. (Physician)

Indeed, the more crowded a clinic was, the more likely the clinic was chosen by a patient as his/her preferred provider.

Some patients don't have to come to our clinic. It is already overloaded. But patients think we are better than community centres. (Manager)

Due to the lack of trust, risk-aversive precautions were taken by health organisations and health workers.

According to our policy, dispensed medicines are not allowed to be returned to pharmacy even if patients have realised that those are not what they want. (Physician)

Increased diagnostic tests and prescriptions were often employed as a strategy by health workers to defend themselves in cases of patient complaints. Defensive strategies might be extended to clinical pathways, medical records and even video monitoring.

Sometimes you don't know what patients want ... It is not us as doctors who want to order so many tests. I prefer to order those rather than risking missing something and being accused by patients [of negligence]. (Physician)

Inadequacy of staffing

'Understaffing', 'not enough time', 'seriously overloaded' and 'high stress level' appeared often as a major theme during the interviews with health workers (table 1). Some senior staff expressed concerns about the lack of experience of junior staff and the detrimental impact of heavy workloads on patient safety.

Indeed, workloads emerged as a significant contributor to four patient safety culture subscales. A workload in the normal or lower range was positively associated with a culture in favour of patient safety (see appendix 9 in online supplement). The regression models showed that clinicians with a heavy workload were less likely to appreciate the contribution of the local manager to patient safety, were less appreciative of the strength of organisational learning and continuous improvement, were less positive about the teamwork between units and were less concerned about the risks of handoffs and transitions (see appendix 7 in online supplement).

Workload was also associated with personal patient safety rating. Those who were overloaded perceived worse patient safety. About $40 \%$ of questionnaire respondents (health workers) who worked more than $60 \mathrm{~h}$ a week rated overall patient safety as 'poor', whereas fewer than $20 \%$ of those working less than 
$60 \mathrm{~h}$ reported poor patient safety. The difference was statistically significant $\left(\chi^{2}=15.27, \mathrm{p}=0.004\right)$.

\section{Factors associated with patient safety culture}

The attitudes of management (local and senior) and subprofessional culture were identified as important factors associated with patient safety culture.

Perceptions of managers (both local and senior) having positive attitudes to safety were associated with a higher estimation of patient safety (see appendix 7 in online supplement). The attitudes of management also had the strongest associations with other culture domains. The correlation analysis of questionnaire data showed that the patient safety culture subscales had weak to medium correlations with each other, with the majority of the medium correlations (21 out of 27) being associated with 'manager expectations and actions promoting safety' (9), 'management support for patient safety' (8) and 'staffing' (7) (see appendix 10 in online supplement).

Overall, the patient safety culture across subprofessions was very similar. However, significant differences appeared in a few patient safety culture dimensions between subprofessional groups. Nurses scored higher in influence of manager/supervisor's 'expectations and actions promoting patient safety' and 'feedback and communication about error' than their doctor and/or administrative counterparts. Administrative staff gave the lowest rating for strength of 'organisational learning and continuous improvement' (table 2).

Indeed, nurses reported more events than doctors. About $82 \%$ of doctors admitted that they had never reported adverse events over the past 12 months. This proportion is much higher than that of nurses $(56 \%)$ and other health workers $(59 \%) \quad\left(\chi^{2}=21.13\right.$, $\mathrm{p}=0.002)$. Doctors reported the least numbers of events $\left(\chi^{2}=21.13, p<0.01\right)$, albeit perceiving similar safety grades as others $\left(\chi^{2}=0.619, p=0.157\right)$. Nurses also scored higher in 'frequency of events reporting' than doctors and administrative staff (table 2). This is perhaps because doctors were less likely than the others to perceive a non-punitive culture (see appendix 7 in online supplement).

Despite the poorer patient safety culture of doctors compared with nurses, patients felt reluctant to challenge doctors. The interviews revealed that a large power distance existed between doctors and patients. They often divulged dissatisfaction (if any) to nurses, perhaps because they perceived nurses as occupying a lower position within the medical hierarchy.

\section{DISCUSSION}

\section{Patient safety culture is important for improving patient} safety

The health workers in this study perceived higher levels of unsafe care but reported fewer events than those from some other countries. ${ }^{12} 2832$ This is not surprising given the negative patient safety culture revealed in this study. The study found that a more positive patient safety culture was associated with staff estimations of patient safety generally. Respondents to this study-regardless of their age, sex, work experience or workload-consistently identified a lack of 'communication openness' as a major safety culture problem. The area with the most potential for

Table 2 Comparison of average positive scores of HOSPC subscales across subprofessional groups

\begin{tabular}{|c|c|c|c|c|c|c|c|c|c|c|}
\hline & \multicolumn{2}{|c|}{ Physician (1) } & \multicolumn{2}{|c|}{$\begin{array}{l}\text { Other health } \\
\text { worker (2) }\end{array}$} & \multicolumn{2}{|c|}{ Nurse (3) } & \multicolumn{2}{|c|}{$\begin{array}{l}\text { Administration/ } \\
\text { management (4) }\end{array}$} & \multirow{2}{*}{$\begin{array}{l}p \text { Value } \\
\text { (ANOVA) }\end{array}$} & \multirow{2}{*}{$\begin{array}{l}\text { Pairwise } \\
\text { comparison } \\
\text { (LSD) } \\
p<0.05\end{array}$} \\
\hline & Mean & SE & Mean & SE & Mean & SE & Mean & SE & & \\
\hline Frequency of events reporting & 0.34 & 0.04 & 0.39 & 0.06 & 0.48 & 0.05 & 0.33 & 0.06 & 0.05 & $\begin{array}{l}\text { (1) vs (3); } \\
\text { (3) vs (4) }\end{array}$ \\
\hline Overall perceptions of patient safety & 0.52 & 0.03 & 0.51 & 0.04 & 0.54 & 0.02 & 0.49 & 0.04 & 0.75 & \\
\hline $\begin{array}{l}\text { Manager expectations and actions } \\
\text { promoting patient safety }\end{array}$ & 0.62 & 0.03 & 0.70 & 0.05 & 0.74 & 0.03 & 0.60 & 0.05 & 0.03 & $\begin{array}{l}\text { (1) vs (3); } \\
\text { (3) vs (4) }\end{array}$ \\
\hline Organisational learning & 0.74 & 0.03 & 0.71 & 0.05 & 0.75 & 0.03 & 0.58 & 0.05 & 0.01 & (4) vs others \\
\hline Teamwork within units & 0.85 & 0.02 & 0.83 & 0.03 & 0.84 & 0.03 & 0.86 & 0.03 & 0.92 & \\
\hline Communication openness & 0.32 & 0.03 & 0.29 & 0.04 & 0.30 & 0.03 & 0.35 & 0.04 & 0.76 & \\
\hline $\begin{array}{l}\text { Feedback and communication about } \\
\text { error }\end{array}$ & 0.63 & 0.03 & 0.61 & 0.06 & 0.64 & 0.04 & 0.51 & 0.05 & 0.15 & $\begin{array}{l}\text { (4) vs (1); } \\
\text { (4) vs (3) }\end{array}$ \\
\hline Staffing & 0.29 & 0.03 & 0.32 & 0.04 & 0.28 & 0.03 & 0.30 & 0.04 & 0.91 & \\
\hline Non-punitive response to error & 0.18 & 0.02 & 0.31 & 0.04 & 0.23 & 0.03 & 0.24 & 0.03 & 0.03 & (1) vs (2) \\
\hline Management support for patient safety & 0.52 & 0.03 & 0.59 & 0.05 & 0.52 & 0.04 & 0.50 & 0.05 & 0.65 & \\
\hline Teamwork across units & 0.56 & 0.03 & 0.68 & 0.05 & 0.58 & 0.04 & 0.48 & 0.05 & 0.05 & $\begin{array}{l}\text { (2) vs (1); } \\
\text { (2) vs (4) }\end{array}$ \\
\hline Handoffs and transitions & 0.48 & 0.03 & 0.45 & 0.05 & 0.54 & 0.03 & 0.43 & 0.06 & 0.28 & \\
\hline
\end{tabular}

Bold type indicates dimensional scores with a significant difference from one or more others across subprofessional groups. HOSPC, Hospital Survey of Patient Safety Culture; LSD, least significant difference. 
improvement also includes non-punitive response to error. Our results showed that the respondents expressed no confidence in the non-punitive policy regarding error reporting and perceived 'penalty' to be the greatest barrier for encouraging the reporting of errors. These findings are consistent with those of several other studies in China. ${ }^{9}$ 44-46

'Teamwork within units' has emerged as an area of strength in almost all HSOPC studies, ${ }^{32}$ 44-46 including in this study. A surprising finding of this study is that teamwork served as a self-defensive mechanism in the medical practice. Unlike Erler $e a^{30}$ who established medium association between 'teamwork within unit' and 'frequency of events reporting', no such association is evident in our study. This might be associated with the Chinese tradition that encourages a doctrine of collectivism. ${ }^{29}{ }^{47}$ Degeling et $a l^{47}$ argued that a strong sense of collective body can be translated into teamwork. However, such teamwork is not necessarily patient-centred. ${ }^{9} 1248$

\section{Patient safety culture is shaped by the institutional and wider social context}

The respondents of this study reported inadequate staffing as another area with the most potential for improvement. In addition, workload emerged as one of the most important factors associated with the staff rating of patient safety culture. Overloaded staff tended to report a worse patient safety culture, and this is consistent with other studies. ${ }^{94}$

Although there is a consensus that doctors play an important role in patient safety, we found that they were less likely to report events and feel confidence in non-punitive approaches to error than their colleagues. Such phenomena are also reflected in patient safety research culture. Nursing-related adverse events have been studied extensively in China; ${ }^{40} \quad 5051$ however, comparatively, there exists a conspicuous gap in research into adverse events in relation to services provided by doctors.

One of the lessons from this study is that patient safety culture is closely associated with the environment in which healthcare services are delivered. Without doubt, Chinese health workers are working in a very difficult and challenging environment. ${ }^{49}$ 52-55 Serious conflict exists between health workers and patients. Over the past three decades the Chinese government has attempted to limit government expenditure while still maintaining a viable medical industry through encouraging providers to raise funds through user charges. Staff remuneration policies in hospitals are commonly linked to servicing volumes and departmental revenues. Notwithstanding big increases in government funding in recent years, these perverse incentives continue to drive over-servicing. ${ }^{54}$ Understandably, consumers become angry and even violent when facing high copayments for services they fear may be unnecessary or if denied essential medical care based on inability to pay. ${ }^{56}$

Patient complaints are commonly settled through payment of financial compensation to consumers, and it appears that the expectation that consumers are predisposed to complain can exacerbate defensive practice. Both patient and health worker participants in this study agreed that doctors tended to use overprovision of services as a strategy to cope with such inherent conflict and defend themselves. Doctors must develop a treatment plan to meet the interests of their patient and also consider the available alternatives which may be more financially beneficial to their organisation. Clinical decision-making often involves a high level of vigilance as doctors weigh possible utilitarian gains and losses for their patients and significant others. ${ }^{57} \mathrm{~A}$ doctor may experience psychological stress if a decision is made that does not benefit the organisation, especially in the context of China where hospital doctors are employees and a great power distance exists between managers and doctors. There is a danger that such an environment may drive doctors into passive compliance or defensive avoidance, leading to a medical culture where doctors do not consider that their practices contribute to the patient safety problem.

\section{Strategies for ensuring patient safety}

It is important to acknowledge that patient safety is dependent upon a systems approach, which requires contributions and collaborations from a wide range of stakeholders and extends beyond the boundary of an individual unit or organisation. International evidence has shown that priorities in patient safety initiatives should be given to a formalised culture and institutional systems and procedures where lessons could be learnt through past errors. ${ }^{58}$

Strong leadership and managerial support is critical to the development of a positive patient safety culture that encourages learning. Our inter-subscale correlation analyses demonstrated that perceived management support is the domain with the strongest associations with other domains of patient safety culture. Unlike the USA, ${ }^{13}$ managers did not perceive the patient safety culture more positively than other staff, which may indicate a greater potential for management improvement. A recent systematic review proved that leadership and managerial support as well as governance structures can have an impact on patient safety culture. ${ }^{11}$

Building trust between providers and consumers and between managers and health workers is essential for empowering health workers to address patient safety issues. The lack of trust is a serious issue of concern in patient care in China. ${ }^{51}$ Without trust, it is unlikely that health workers will endorse the idea of open communication and fostering outcome learning from errors. 
Patient safety activities should align with cultural values prized by Chinese people. Meanwhile, however, institutional and administrative arrangements should encourage involvement of frontline practitioners and consumers in policy development and management decisions. As is noticed by some observers, the cultural values of Chinese consumers are changing and they are demanding a greater voice in policy and management decisions. ${ }^{59}$

\section{Limitations and further studies}

This study was undertaken in two clinics in one hospital. Further research is needed to extend the scope and sample size. There is also a need to test the association between patient safety culture and quality of patient care, in which patient centeredness should become a key element of measurement. In a recent pilot study we confirmed that participation in management decisions is positively associated with doctors' perceptions on quality of care. ${ }^{60}$

Acknowledgements The authors thank Nittita Prasopa-Plaizier for her technical advice, all those who participated in the study, David Legge for his academic advice in writing and Adamm Ferrier for his proofreading and editing support. They are also grateful to the valuable comments made by the anonymous reviewers.

Contributors CL and WL conceived the concept and design of the study and supervised the data collection. YW, ZZ and PW participated in the design of the study and acquisition and interpretation of data. CL led the data analyses and writing of the manuscript. All authors contributed to the drafting of the article and read and approved the final version of the manuscript.

Funding This study was supported by a WHO Patient Safety Small Grant (PS09029), a La Trobe University health sciences faculty grant and the participating hospital.

\section{Competing interests None.}

Ethics approval Human research ethics approval was obtained from the WHO, La Trobe University and the participating organisation.

Provenance and peer review Not commissioned; externally peer reviewed.

Open Access This is an Open Access article distributed in accordance with the Creative Commons Attribution Non Commercial (CC BY-NC 3.0) license, which permits others to distribute, remix, adapt, build upon this work noncommercially, and license their derivative works on different terms, provided the original work is properly cited and the use is non-commercial. See: http://creativecommons.org/licenses/by$\mathrm{nc} / 3.0 /$

\section{REFERENCES}

1 Institute of Medicine. To err is human: building a safer health system. Washington, DC: National Academics Press, 1999.

2 Baker GR, Norton PG, Flintoft V, et al. The Canadian adverse events study: the incidence of adverse events among hospital patients in Canada. CMAJ 2004;170:1678-86.

3 Brennan TA, Leape LL, Laird NM, et al. Incidence of adverse events and negligence in hospitalized patients: results of the Harvard Medical Practice Study I. 1991. Qual Saf Health Care 2004;13:145-51; discussion 151-2.
4 Davis P, Lay-Yee R, Briant R, et al. Adverse events in New Zealand public hospitals I: occurrence and impact. NZ Med J 2002;115:U271.

5 Ehsani JP, Jackson T, Duckett SJ. The incidence and cost of adverse events in Victorian hospitals 2003-04. Med J Aust 2006;184:551-5.

6 Catchpole K, Bell MD, Johnson S, et al. Safety in anaesthesia: a study of 12,606 reported incidents from the UK National Reporting and Learning System. Anaesthesia 2008;63:340-6.

7 Cresswell KM, Sheikh A. Lessons from the UK National Patient Safety Agency's National Reporting and Learning System on reducing drug allergies. Prim Care Respir J 2008;17:3-4.

8 Dovey SM, Meyers DS, Phillips RL, et al. A preliminary taxonomy of medical errors in family practice. Qual Saf Health Care 2002;11:233-8.

9 Nie Y, Mao X, Cui H, et al. Hospital survey on patient safety culture in China. BMC Health Serv Res 2013;13:228.

10 World Health Organization. Patient safety: a global priority. Geneva: World Health Organization, 2006.

11 Weaver SJ, Lubomksi LH, Wilson RF, et al. Promoting a culture of safety as a patient safety strategy: a systematic review. Ann Intern Med 2013;158(5 Pt 2):369-74.

12 Fujita S, Seto K, Ito $S$, et al. The characteristics of patient safety culture in Japan, Taiwan and the United States. BMC Health Serv Res 2013;13:20.

13 Clancy CM. New research highlights the role of patient safety culture and safer care. J Nurs Care Qual 2011;26:193-6.

14 Vincent CA. Analysis of clinical incidents: a window on the system not a search for root causes. Qual Saf Health Care 2004;13:242-3.

15 Lewin K. Group decision and social change. New York: Holt, Rinehart and Winston, 1958.

16 World Alliance for Patient Safety. WHO draft guidelines for adverse event reporting and learning systems. Geneva: World Health Organization, 2005.

17 Hoffmann B, Beyer M, Rohe J, et al. "Every error counts": a web-based incident reporting and learning system for general practice. Qual Saf Health Care 2008;17:307-12.

18 Hutchinson A, Young TA, Cooper KL, et al. Trends in healthcare incident reporting and relationship to safety and quality data in acute hospitals: results from the National Reporting and Learning System. Qual Saf Health Care 2009;18:5-10.

19 Williams SK, Osborn SS. The development of the National Reporting and Learning System in England and Wales, 20012005. Med J Aust 2006;184(10 Suppl):S65-8.

20 Ashcroft DM, Morecroft C, Parker D, et al. Likelihood of reporting adverse events in community pharmacy: an experimental study. Qual Saf Health Care 2006;15:48-52.

21 Mardon RE, Khanna K, Sorra J, et al. Exploring relationships between hospital patient safety culture and adverse events. J Patient Saf 2010;6:226-32.

22 Jackson J, Sarac C, Flin R. Hospital safety climate surveys: measurement issues. Curr Opin Crit Care 2010;16:632-8.

23 Robb G, Seddon M. Measuring the safety culture in a hospital setting: a concept whose time has come? NZ Med J 2010;123:68-78.

24 Nieva V, Sorra J. Safety culture assessment: a tool for improving patient safety in health care organizations. Qual Saf Health Care 2003;12:17-23.

25 Sorra JS, Dyer N. Multilevel psychometric properties of the AHRQ hospital survey on patient safety culture. BMC Health Serv Res 2010;10:199. 
26 Smits M, Christiaans-Dingelhoff I, Wagner C, et al. The psychometric properties of the 'Hospital Survey on Patient Safety Culture' in Dutch hospitals. BMC Health Serv Res 2008;8:230.

27 Sammer CE, Lykens K, Singh KP, et al. What is patient safety culture? A review of the literature. J Nurs Scholarsh 2010;42:156-65.

28 Bodur S, Filiz E. A survey on patient safety culture in primary healthcare services in Turkey. Int J Qual Health Care 2009;21:348-55.

29 Chen IC, Li H-H. Measuring patient safety culture in Taiwan using the Hospital Survey on Patient Safety Culture (HSOPSC). BMC Health Serv Res 2010;10:152.

30 Erler C, Edwards NE, Ritchey S, et al. Perceived patient safety culture in a critical care transport program. Air Med J 2013;32:208-15.

31 Lemer C, Moss F. Patient safety and junior doctors: are we missing the obvious? BMJ Qual Saf 2013;22:8-10.

32 Wagner C, Smits M, Sorra J, et al. Assessing patient safety culture in hospitals across countries. Int J Qual Health Care 2013;25:213-21.

33 Zhu J, Li L, Li Y, et al. What constitutes patient safety culture in Chinese hospitals? Int J Qual Health Care 2012;24:250-7.

34 World Health Organization. The world health report 2008: primary health care now more than ever. Geneva: World Health Organization, 2008.

35 Blendon R, DesRoches C, Brodie M, et al. Views of practicing physicians and the public on medical errors. $\mathrm{N}$ Engl J Med 2002;347:1933-40.

36 Adams R, Boscarino J. A community survey of medical errors in New York. Int J Qual Health Care 2004;16:353-62.

37 Rosser W, Dovey S, Bordman R, et al. Medical errors in primary care: results of an international study of family practice. Can Fam Physician 2005;51:387.

38 Ministry of Health. National health statistics digest. Beijing: Ministry of Health, 2012.

39 Zhao Y, Chen HZ. Factors associated with medical adverse events. Lab Med Clin Pract 2010(06):568-70.

40 Xuanyue M, Yanli N, Hao C, et al. Literature review regarding patient safety culture. J Evid Based Med 2013;6:43-9.

41 van Noord I, de Bruijne MC, Twisk JWR. The relationship between patient safety culture and the implementation of organizational patient safety defences at emergency departments. Int J Qual Health Care 2010;22:162-9.

42 Draper NR, Smith H. Applied regression analysis. Hoboken, NJ: Wiley-Interscience, 1998.

43 Liamputton P, Ezzy D. Qualitative research methods. Melbourne: Oxford University Press, 2005.
44 Chen L, Zhu ZM, Wang DY. Factors determining the report of nursing adverse events. PLA Nurs J 2010(08):628-29.

45 Fang LY, Wang JN, Qiao GH. Factors associated with the report of adverse nursing events. Nurs J 2010(10):54-6.

46 Liu Y, Kalisch BJ, Zhang L, et al. Perception of safety culture by nurses in hospitals in china. J Nurs Care Qual 2009;24:63-8.

47 Degeling P, Zhang K, Coyle B, et al. Clinicians and the governance of hospitals: a cross-cultural perspective on relations between profession and management. Soc Sci Med 2006;63:757-75.

48 Pun K-F, Chin K-S, Lau H. A review of the Chinese cultural influences on Chinese enterprise management. Int J Manag Rev 2000;2:325-38.

49 Aiken LH, Sloane DM, Clarke S, et al. Importance of work environments on hospital outcomes in nine countries. Int $J$ Qual Health Care 2011;23:357-64.

50 Liu Y, Zhao G, Li F, et al. Nursing-related patient safety events in hospitals. J Huazhong Univ Sci Technol Med Sci 2009;29:265-8.

51 Feng X, Bobay K, Krejci JW, et al. Factors associated with nurses' perceptions of patient safety culture in China: a cross-sectional survey study. J Evid Based Med 2012;5:50-6.

52 Lancet T. Chinese doctors are under threat. Lancet 2010;376:657.

53 Sun S, Wang W. Violence against Chinese health-care workers. Lancet 2010;377:1747.

54 Yip WC, Hsiao W, Meng Q, et al. Realignment of incentives for health-care providers in China. Lancet 2010;375:1120-30.

$55 \mathrm{Yu} \mathrm{D}, \mathrm{Li}$ T. Doctor stabbed to death two days after warning. Lancet 2011;377:639.

56 Zheng P, Faunce T, Johnston K, et al. Public hospitals in China: privatisation, the demise of universal health care and the rise of patient-doctor violence. J Law Med 2006;13:465-70.

57 Chambers KB, Rew L, Chambers KB, et al. Safer sexual decision making in adolescent women: perspectives from the conflict theory of decision-making. Issues Compr Pediatr Nurs 2003;26:129-43.

58 Patterson M, Rick J, Wood S, et al. Systematic review of the links between human resource management practices and performance. Health Technol Assess 2010;14:1-334.

59 Polsa P, Wei F, Saaksjarvi M, et al. Cultural values and health service quality in China. Int J Health Care Qual Assur 2013;26:55-73.

60 Liu C. International health human resources management. In: Mao JF. ed Health human resources management. Beijing: People's Medical Publishing House, 2013:366-90. 